\title{
Siparuna guianensis Aublet (negramina): uma revisão
}

\begin{abstract}
VALENTINI, C.M.A. ${ }^{1 *}$; RODRÍGUEZ-ORTÍZ, C.E. ${ }^{2}$; COELHO, M.F.B. ${ }^{3}$
${ }^{1}$ Instituto Federal de Educação, Ciência e Tecnologia de Mato Grosso (IFMT), Campus Cuiabá - Bela Vista, Av. Juliano Costa Marques, s/n, Bairro Bela Vista. CEP: 78.050-560, Cuiabá-Brasil *carla.valentini@blv.ifmt.edu.br ${ }^{2}$ Instituto de Biociências, Universidade Federal de Mato Grosso, Av. Fernando Corrêa da Costa, s/n, CEP: 78060900, Cuiabá-Brasil ${ }^{3}$ Departamento de Ciências Vegetais, Universidade Federal Rural do Semi-Árido, Km 47 da BR 110. Bairro Pres. Costa e Silva, CEP:59625-900, Mossoró-Brasil
\end{abstract}

\begin{abstract}
RESUMO: As pesquisas realizadas a partir de recursos genéticos de espécies medicinais nativas somente serão aplicadas se o material genético estiver seguro quanto à sobrevivência e disponibilidade. O objetivo deste artigo foi realizar uma revisão bibliográfica adotando como critério a escolha de artigos publicados em conceituadas revistas nacionais e internacionais, que permitissem melhor entendimento dos aspectos etnobotânicos, ecológicos e químicos de importante planta medicinal e aromática: Siparuna guianensis Aublet. Como tem sido apontada como uma das espécies prioritárias de conservação para a região do cerrado brasileiro, os estudos da propagação devem ser incentivados para que este recurso genético esteja disponível às gerações futuras.
\end{abstract}

Palavras-chave: etnofarmacologia, fitoquímica, propagação, cerrado, plantas medicinais

ASTRACT: Siparuna guianensis Aublet ("negramina”): a review. Studies with genetic resources of native medicinal species will only be applied if their genetic material is safe regarding survival and availability. The aim of this study was to do a literature review adopting as criterion the choice of papers published in renowned national and international journals to allow better understanding on ethnobotanical, ecological and chemical aspects of an important medicinal and aromatic plant, Siparuna guianensis Aublet. Since the latter has been considered one of the major species for the conservation of Brazilian cerrado, studies on its propagation should be encouraged in order to make this genetic resource available to future generations.

Key words: Ethnopharmacology, phytochemistry, propagation, cerrado, medicinal plants

\section{INTRODUÇÃO}

As pesquisas realizadas a partir de recursos genéticos de espécies medicinais nativas somente serão aplicadas se o material genético estiver seguro quanto à sobrevivência e disponibilidade. Por isso, são necessários estudos que investiguem a melhor forma de propagação para que se desenvolva o cultivo e manejo (Albuquerque et al., 2003).

O Brasil possui cinco áreas de grande abundância de plantas nativas, estando entre elas 0 bioma Cerrado, que está entre os 34 "hotspots", as mais ricas e mais ameaçadas reservas da biodiversidade da Terra. Apenas 2,2\% da área do cerrado encontra-se legalmente protegida e, somando-se ao problema, estima-se que $20 \%$ das espécies ameaçadas ou endêmicas não ocorram nas áreas legalmente protegidas (Klink \& Machado, 2005). É preciso considerar que os recursos naturais oferecidos por este bioma, uma vez extintos, estarão indisponíveis às futuras gerações. Entre estes, podese considerar o recurso terapêutico oferecido pelas plantas medicinais (Guarim Neto \& Morais, 2003).

O objetivo deste artigo foi realizar revisão bibliográfica, adotando como critério a pesquisa documental a partir de artigos e livros publicados em conceituadas revistas nacionais e internacionais especializadas em plantas medicinais, que permitissem melhor entendimento dos aspectos etnobotânicos, ecológicos e químicos de importante

Recebido para publicação em 03/07/2008

Aceito para publicação em 19/11/2009

Rev. Bras. PI. Med., Botucatu, v.12, n.1, p.96-104, 2010. 
planta medicinal e aromática: Siparuna guianensis Aublet, que vem sendo apontada por estudiosos como espécie prioritária de conservação para a região do cerrado. As buscas, utilizando-se palavras-chaves, foram realizadas em bases de dados científicos como - Scielo, portal "Periódicos" da CAPES (Coordenação de Aperfeiçoamento de Pessoal de Nível Superior), acervo bibliográfico de bibliotecas universitárias via sistema COMUT (Comutação Bibliográfica), além de pedidos diretos aos próprios autores, que também indicaram algumas referências e sites que julgavam importantes para o estudo. Não foram estabelecidos períodos específicos de publicação, mas a relevância das informações contidas nas mesmas.

\section{Características da família e gênero}

Apesar da Siparuna ser reconhecida por muitos taxonomistas como pertencente a família Monimiaceae e citada sob essa classificação em inúmeros artigos, o sistema APG II (Grupo para a Filogenia das Angiospermas), de 2003, segregou o gênero Siparuna Aublet, reconhecendo-o como sendo da família Siparunaceae, o que será também adotado nesta revisão.

Siparunaceae consiste em dois gêneros, Glossocalyx, uma espécie da África Ocidental, e Siparuna, com aproximadamente 65 espécies nos neotrópicos, a maior parte nos Andes (Renner, 1997). A única espécie de Glossocalyx reconhecida é uma arvoreta, que geralmente não ultrapassa 12 metros de altura. O gênero Siparuna compreende espécies de arbustos e arvoretas, exceto para 15 espécies que são árvores de 20 a 40 metros de altura, com troncos com diâmetros maiores que $120 \mathrm{~cm}$, que ocorrem geralmente na Amazônia (Renner \& Hausner, 2005).

$O$ gênero Siparuna ocorre na maioria dos tipos de vegetação neotropical em elevações entre o nível do mar e 3800 metros (Renner \& Hausner, 2005). Comparando a escassa presença no Velho Mundo Tropical (uma espécie), Siparunaceae tem se diversificado de forma impressionante nos Andes (45 espécies). Baseado nesta atual distribuição, Siparunaceae poderá ser uma grande família ocidental. As espécies filogeneticamente basais desta família ocorrem em todas as áreas da planície Amazônica e nas áreas protegidas das Guianas, sugerindo que este grupo inicialmente diversificou depois da adaptação em grandes altitudes, como nas elevações dos Andes.

\section{Características da espécie}

Siparuna guianensis foi a primeira espécie de Siparuna descrita e ilustrada por Aublet na Histoire des plantes de La Guiana Françoise (1775). Ocorre desde a Nicarágua, por todo o norte da América do Sul até o Paraguai, em planícies de florestas primárias e secundárias elevadas, com alturas de 1200 metros, raramente de 1400 metros (Renner \& Hausner, 2005), como pode ser observado na Figura 1.

Possui as sinonímias Citriosma camporum Tul.; Citriosma discolor Poepp. \& Endl.; Citriosma guianensis (Aubl.) Tul.; Citriosma guianensis var. divergentifolia Pohl ex Tul.; Citriosma guianensis var. nuda Tul.; Siparuna archeri A. C. Smith; Siparuna

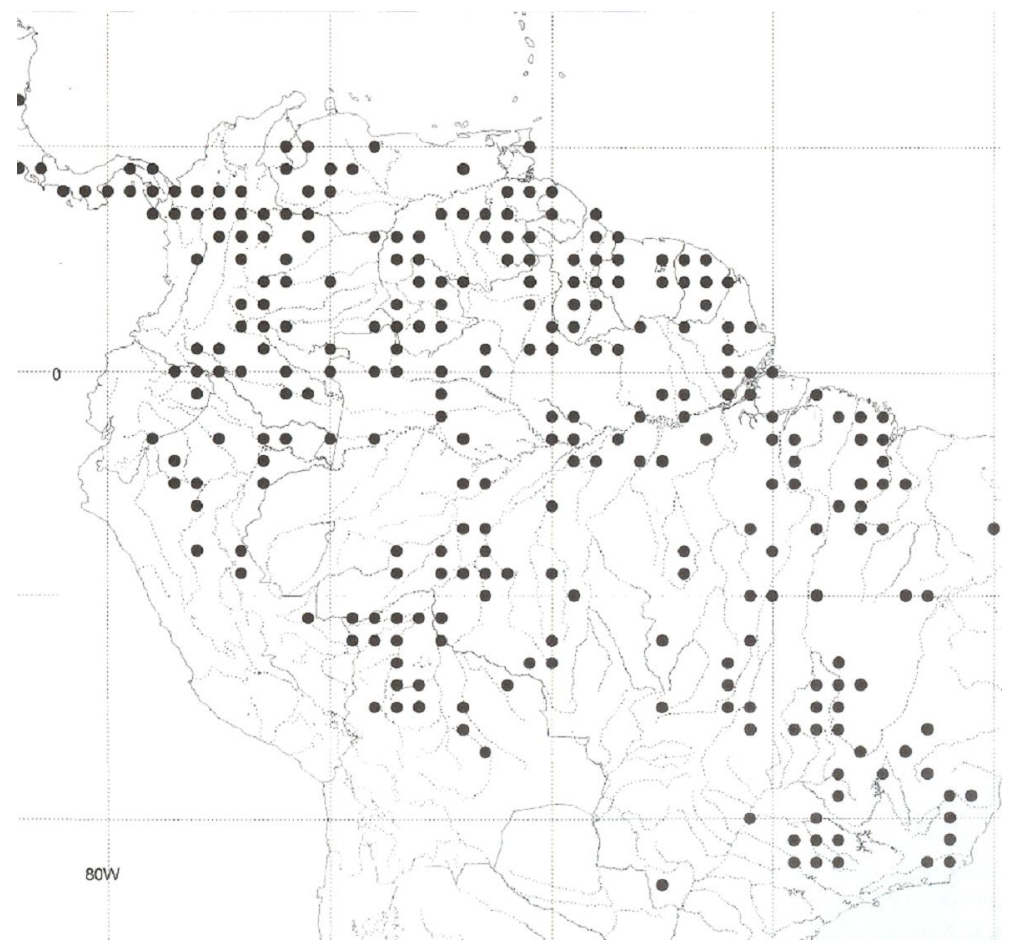

FIGURA 1. Locais de ocorrência da S. guianensis. Fonte: Renner \& Hausner (2005). 
camporum (Tul.) A.DC.; Siparuna arianeae M. V. L. Pereira; Siparuna cavalcanteiJangoux; Siparuna discolor (Poepp. \& Endl.) A.DC.; Siparuna duckeana Jangoux; Siparuna foetida Barb.Rodr.; Siparuna guianensis var. glabrescens A.DC.; Siparuna guianensis var. longifolia A.DC.; Siparuna guianensis var. nitens Kuntze; Siparuna itacaiunensis Jangoux; Siparuna panamensis A.DC. e Siparuna savanicola Jangoux.

Esta espécie é conhecida por vários nomes populares de acordo com o país e/ou região de distribuição no Brasil. No cerrado dos estados de Mato-Grosso e Goiás, é conhecida pelo nome de negramina (Carmona \& Guarim Neto, 2001; Souza \& Felfili, 2006) e, no cerrado de Minas Gerais além de negramina (Rodrigues \& Carvalho, 2001), é conhecida como folha-santa (Herrmann et al., 1998) e marinheiro (Souza et al., 2007). No Pará é chamada de capitiú (Alvino et al., 2005), mata-cachorro e catingoso (Martins Filho, 2006). No Paraná, é conhecida por capitiú, limão-bravo e cicatrizante-das-guianas (Furtado, 2006). No Distrito Federal, é chamada de limão-bravo (Viani \& Rodrigues, 2007) e erva-santa (Pereira \& Silva, 2008). No interior de São Paulo, é chamada amescla-de-cheiro (Rodrigues, 1999; Approbato \& Godoy, 2006) e mata-cachorro (Cielo Filho \& Santin, 2002). Em Pernambuco, é conhecida como jaqueira (Costa Jr. et al., 2007) e catingueirade-paca (Lôbo et al., 2007) e no Rio de Janeiro, como fedegoso (Christo et al., 2006), entre outros.

O grupo ecológico foi classificado como de clímax exigente de luz por Davide et al. (1995) e Ressel et al. (2004); como clímax tolerante à sombra por Nunes et al. (2003) e Pinto et al. (2005), e como secundária por Souza et al. (2006).

São arbustos ou arvoretas (Figura 2) monóicos, 5-9 (-15) metros de altura, alcançando um diâmetro na altura do peito de $20 \mathrm{~cm}$; casca cinza e lisa, pequenos ramos jovens cilíndricos, mas achatados nos nós, com insignificantes pêlos estrelados .

Possuem folhas simples, membranáceas, de margens lisas, opostas; pecíolos de 0,5-1,5 cm de comprimento, são alongadas a elípticas ou lanceoladas, com 10-22 (-33) x 4-10 (-16) cm, a base obtusa, o ápice acuminado, inclinado 0,5-1 cm de comprimento, a superfície inferior com 9-11 pares de nervuras secundárias levemente salientes em cima (Renner \& Hausner, 2005), como é mostrado na Figura 3.

A inflorescência se dá em cachos diretamente sub-ligados e agrupados, com $1-1,5 \mathrm{~cm}$ de comprimento, e de forma compacta coberta de pêlos estrelados com 5-15 flores. Novas flores são amarelas-esverdeadas; flores machos em formato de copo, com 2-3 mm de diâmetro, e 1,5-2,5 mm de altura, 4-6 pétalas insignificantes, de modo geral triangulares, com cerca de $0,2 \mathrm{~mm}$ de comprimento, botão floral quase desenvolvido, 10-18 estames, membranáceo distalmente estreito. Flores fêmeas são

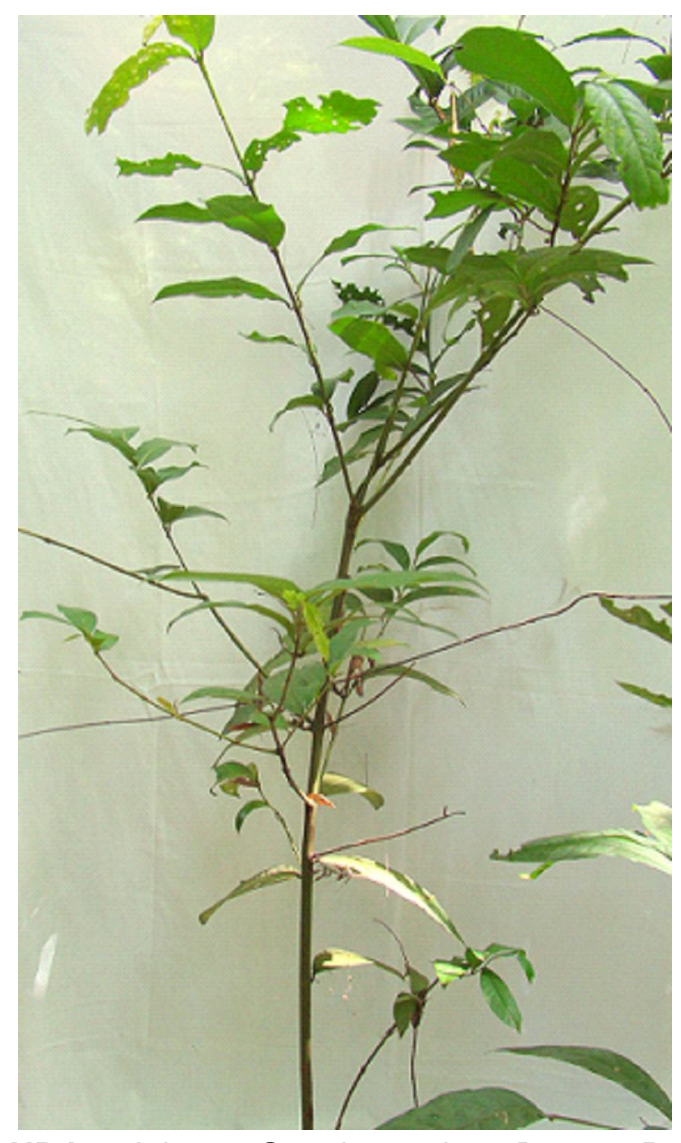

FIGURA 2. Arbusto S. guianensis no Bosque Paulo Siqueira, Cuiabá-MT. (Foto por Valentini, C.M.A.).

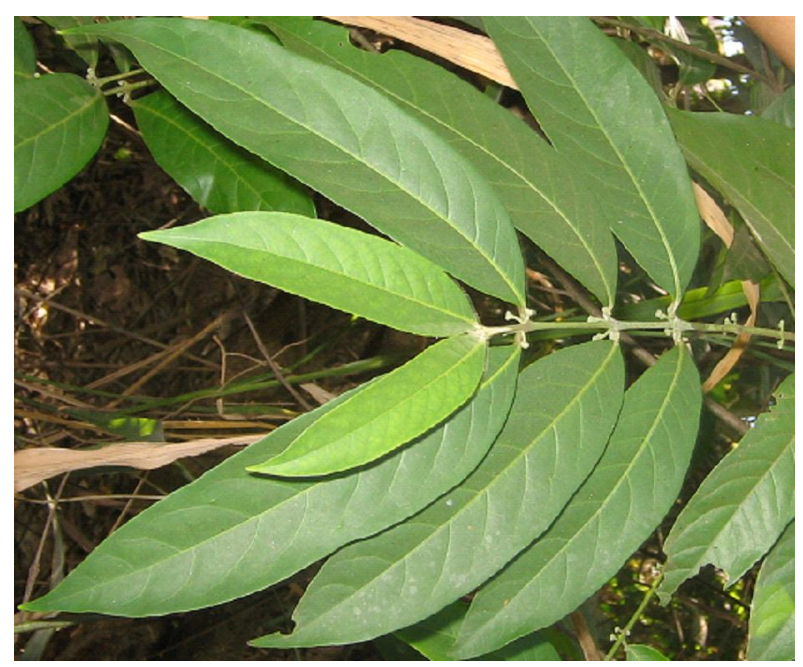

FIGURA 3 . Folhas de S. guianensis do Bosque Paulo Siqueira, Cuiabá-MT (Foto por Valentini, C.M.A.).

ovóides a subglobosas, com 1,8-2,5 mm de diâmetro, e 2,5-3 mm de altura, com pétalas como nas flores machos, botão floral cônico, 3-12 (-17) carpelos; 5-7 estilos expostos, livres ou formando uma coluna (Renner \& Hausner, 2005). A Figura 4 apresenta a espécie na fenofase de floração coletada no Parque Massairo Okamura, localizado em Cuiabá-MT. 


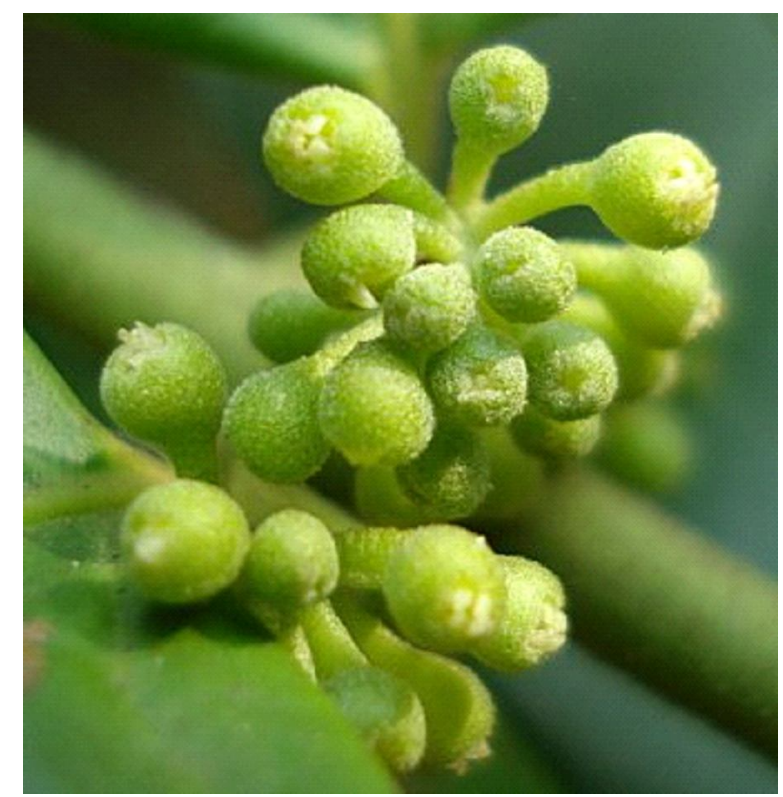

FIGURA4. Flores de S. guianensis (Foto por Valentini, C.M.A.).

O receptáculo frutífero (frutos ou pseudofrutos, dependendo da preferência de terminologia) é múltiplo cupuliforme, globoso, densamente coberto com pêlos estrelados, desprovidos de cobertura estilar, com 0,68$1,32 \mathrm{~cm}$ de comprimento $\times$ 0,67-1,37 cm de diâmetro, cúpula receptacular siconiforme. Os receptáculos novos e maduros exalam odor fortemente desagradável, freqüentemente cítricos; são vermelhoesverdeados e racham para abrir e expor o interior amarelado e revelar as sementes (4-10 sementes). Abrem-se irregularmente formando câmaras com frutíolos drupóides elipsóides, papilosos, recobertos por excrescência carnosa branca, com 4,2-5,8 mm de comprimento $\times$ 3,6-4,5 mm de diâmetro. Há uma semente por frutíolo, elipsóide, bege, 4,2-5,8 $\mathrm{mm} \times$ 2,5-3 mm de diâmetro testa lisa (Renner \& Hausner, 2005; Approbato \& Godoy, 2006). As Figuras 5 e 6 mostram a $S$. guianensis (Bosque Paulo Siqueira, Cuiabá-MT) na fenofase de frutificação, com frutos verdes e maduros, respectivamente.

\section{Polinização e dispersão}

A reprodução de plantas tropicais depende, essencialmente, da interação com animais polinizadores e/ou dispersores de sementes, uma vez que as angiospermas dependem dos animais para 0 transporte de pólen ou de sementes.

A polinização foi estudada em 11 espécies dióicas nos Andes e leste do Equador (Feil \& Renner, 1991; Feil, 1992), três espécies dióicas nos Andes da Colômbia (Feil, 1992; Peña Paz, 2000) e seis espécies monóicas na região central da Amazônia (Schulz-Burck, 1997). Os dados para essas 19 espécies e mais as observações do material do herbário (por exemplo, flores contendo larvas) sugerem que as formas de polinização são idênticas em todo o gênero.

Siparuna é polinizada durante a noite por inquietos mosquitos (Díptera: Cecidomyiidae) pertencentes aos gêneros Asynapta (Asynaptini), Clinodiplosis (Clinodiplosini) e Dasineura (Oligotrophini). Os mosquitos adultos têm cerca de três milímetros de comprimento e capacidade de vôo direcionado. Eles são noturnos e põem seus ovos nos locais pelo olfato (Gagné, 1994).

Mosquitos fêmeas pousam sobre as flores, inserem o abdômen na abertura do botão floral e, então, movem-se ritmicamente por sobre ele um ou dois minutos durante o qual elas depositam os ovos nas flores. Os abdômens dos cecidomyiidaes produzem longos pêlos, entre os quais os grãos de pólen se alojam (Feil, 1992).

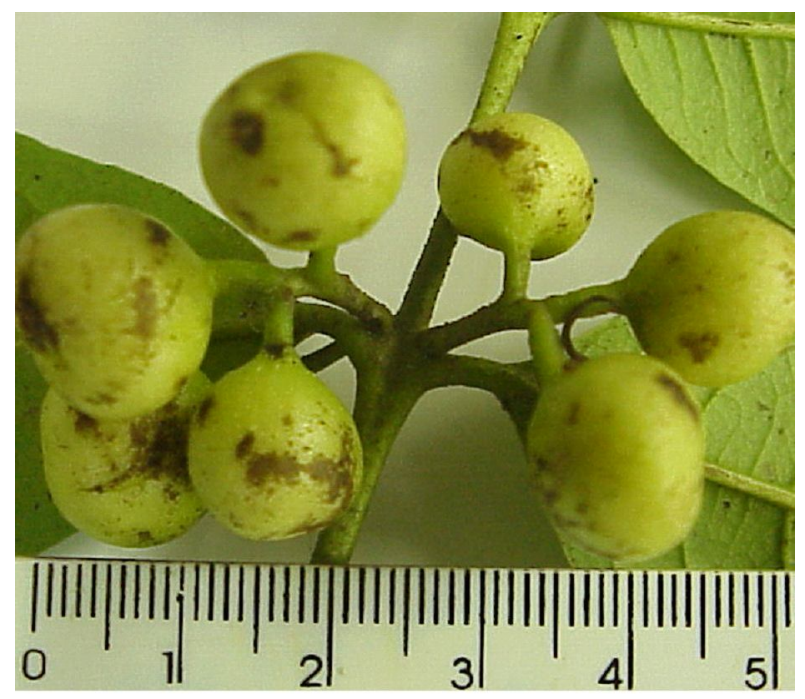

FIGURA 5. Frutos verdes de S. guianensis (Foto por Coelho, M.F.B.).

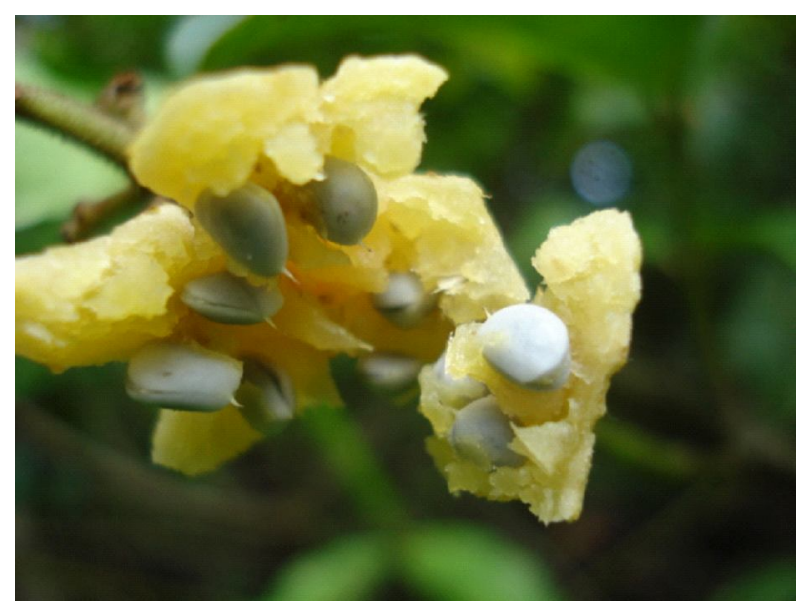

FIGURA 6. Frutos maduros de $S$. guianensis (Foto por Almeida, J.D.). 
Oliveira \& Paula (2001), Nunes et al. (2003), Takahashi \& Fina (2004) e Pinto et al. (2005) classificaram os frutos da espécie como zoocóricos (diásporos adaptados à dispersão por animais, como aves e mamíferos) devido às polpas adocicadas, sementes com arilos, etc.

Os principais dispersores de Siparuna são pássaros papa-moscas, de barriga cor ocre (marromamarelado), cujo nome é Mionectes oleagineus (Lichtenstein, 1823) e os de listra no pescoço, chamado Mionectes striaticollis (Orbigny \& Lafresnaye, 1837), que vivem do sul do México até o Peru, Bolívia, Brasil, e também ocorrem em Trinidad e Tobago (Peña Paz, 2000). Esses pássaros, freqüentemente, pegam receptáculos maduros e, então, voam para lugar seguro onde eles picam as sementes para a perfuração, trabalhando uma por uma, e ingerindo-as inteiras. As sementes são dispersas via excreção das fezes (Renner \& Hausner, 2005).

A cobertura polpuda ou viscosa do exo-/ mesocarpo sobre as sementes expostas de Siparuna são também atrativos para formigas (Mirmecocoria), como Pachycondyla villosa Fabricius (Feil, 1992). Jangoux (1991) observou ávidas formigas carregando para fora sementes expostas de Siparuna guianensis. Ferreira et al. (2007) testaram, com espécies da fitofisionomia do Cerrado, a remoção de sementes por formigas, roedores e aves, e concluíram que para a $S$. guianensis a mirmecoria representou a maior taxa $(86,9 \%)$ de remoção das sementes expostas. Já, em área de floresta secundária de Minas Gerais, Simas et al. (2001) observaram a dispersão das sementes desta espécie por primatas Callithrix flaviceps.

\section{Etnobotânica}

Em muitos países da América, a decocção de folhas da $S$. guianensis é usada como bebida contra as desordens estomacais. As folhas são usadas para compressas ou cataplasmas contra dor de cabeça e reumatismo. No Panamá e Guiana, extratos são usados para matar insetos daninhos ou como inseticidas. Na Guiana, as folhas são também usadas para preparar armadilhas para peixes devido ao típico odor da espécie que disfarça o cheiro humano. Nas vizinhanças do Suriname, a decocção feita das folhas é usada como bebida ou para banho depois do parto (Renner \& Hausner, 2005). Vigneron et al. (2005), num estudo na Guiana Francesa com diferentes grupos e nacionalidades (Criolos, Palikur, Galibi, Brasileiros e Europeus), encontraram que as folhas de Siparuna guianensis, combinadas com folhas de Campomanesia spp.(Myrtaceae), são usadas como remédio anti-malária.

No Rio Amazonas, região das Guianas, as folhas são preparadas como chá e tomadas para frios, febres, pressão arterial alta, para doenças reumáticas e também contra cólicas (Prance, 1972; Santos \& Peixoto, 2001). Os índios Palikur, que vivem na região do rio Oiapoque no Amapá, usam externamente as folhas moídas com sal para o preparo de cataplasma antiinflamatório ou o decocto para uso na forma de banho durante o parto. Os índios Wayãpi, no Amazonas, tomam o decocto das folhas e da casca do caule para frios, gripe e febre, administrando-o oralmente em pequenas quantidades, mas principalmente na forma de banhos (Grenand et al., 1987 apud Lorenzi \& Matos, 2002).

Os índios Tikuna, maior grupo de índios que ainda permanecem próximo ao rio Amazonas, na região de fronteira do Peru, Colômbia e Brasil, comem os frutos para dispepsia e indigestão; os Kubeo, que vivem no alto do rio Negro, usam as folhas para mordedura de serpente e fazem chá dos frutos para aliviar congestão nasal e frios; os Waorani, tribo equatoriana, esmagam os frutos e folhas para fazer mistura pungente que é esfregada no rosto e cabeça para tratar "dor de cabeça de febre" e a infusão das folhas é empregada como febrífugo. Os índios Tacana, grupo étnico da Amazônia boliviana, usam decocção das folhas como uso externo para gripe (Bourdy et al., 2000). Os índios Yanomami, que vivem numa área de floresta tropical na região da fronteira Brasil e Venezuela, esfregam as folhas amassadas na cabeça e corpo para vertigem (Milliken \& Albert, 1996). Na Colômbia, o chá de folhas é recomendado para reumatismo.

No Equador, os Quechuas tratam herpes aplicando a casca aquecida nas áreas infeccionadas, enquanto as folhas aromáticas são esfregadas na testa e fortemente inaladas para tratar dor de cabeça. Os brasileiros usam decocto das folhas como carminativo e estimulante, enquanto pessoas no Panamá usam decocto de folha para frios, gás intestinal e mordedura de serpente. O Surinamês usa decocto das folhas como banho antes do parto. As cascas dos frutos são tóxicas para animais, pois são ricas em alcalóides benzilisoquinoleínico, porém os macacos Callithrix flaviceps da Estação Biológica de Caratinga, no sudeste do Brasil, esperam os frutos abrirem e exporem as sementes para consumi-las, desprezando as cascas (Duke, 2008).

Rodrigues et al. (2002) citaram o uso da espécie pela população de Luminárias (Minas Gerais) como tendo poderes sobrenaturais, em banho de descarrego, e no mercado de Madureira (Rio de Janeiro), segundo Arjona et al. (2007), a espécie também é vendida para esta finalidade.

Na comunidade Mumbuca, em Jalapão, no Tocantins, faz-se o uso de infusão como analgésico (Rocha-Coelho \& Santos, 2008). Na região do Alto do Rio Grande, em Minas Gerais, faz-se uso do decocto ou infuso de toda a planta como antiinflamatório, 
carminativo, estimulante, nas cefalalgias, nas gripes e resfriados. O cataplasma, a compressa ou o banho são usados para reumatismo (Rodrigues \& Carvalho, 2001). Souza \& Felfili (2006) também citaram o uso pela população de Alto Paraíso de Goiás para coluna, reumatismo e artrite. Christo et al. (2006) encontraram em estudo de comunidades rurais limítrofes à Reserva Biológica de Poço das Antas, no Rio de Janeiro, o uso do caule como combustível para fogões e fornos.

No estado de Mato Grosso, foram realizados alguns estudos etnobotânicos com a espécie e, neles, é citada pelo nome vulgar de negramina. Carmona \& Guarim Neto (2001) relataram que no leste do estado as folhas da espécie são utilizadas na forma de banho para sinusite. Souza (1992) também relata, em pesquisa com moradores da comunidade ribeirinha do Coxipó do Ouro, o uso das folhas em banho para dores no corpo. No Alto Coité, em Poxoréo, as pessoas utilizam um semonte - folhas secas junto ao fogo, moídas e misturadas ao fumo ou puras, para cheirar e uso tópico - para curar "malina", que é descrita como dor de cabeça causada pela exposição demasiada ao sol, que provoca corrimento de sangue nasal (Somavilla, 1998). No Vale do Aricá, município de Cuiabá, as folhas são utilizadas na forma de chá e banhos para fraqueza e também para malina (Pasa, 1999) e, na Aldeia Pakueran, em Paranatinga, as folhas são fervidas, e utilizadas em banho para febre e "quentura" na cabeça, espécie de enxaqueca (Schimöller, 1997).

Em Nova Xavantina, o sumo das folhas com mastruz - Chenopodium ambrosioides L. (Chenopodiaceae) - é relatado como medicinal para pós-operatório. As folhas são utilizadas como repelentes, nos galinheiros, para piolho de galinha e, também, para uso em rituais espirituais (Duarte, 2001). Fontelle (1997) relatou em pesquisa as indicações de raizeiros, que recomendam o uso da folha na forma de decocto e infuso para malina, resfriado e banho de descarrego para mau olhado, podendo, para isso, ser associada à quina (gênero Cinchona), assim como para hipetermia e hemoptise.

\section{Composição química}

Os dados avaliados têm mostrado que a composição dos óleos de folhas frescas e secas, assim como do caule e frutos, muda entre diferentes países, até mesmo entre diferentes regiões geográficas no mesmo país, e dentro da mesma região de acordo com as estações do ano.

Braz Filho et al. (1976) obtiveram com troncos da espécie amostrados, próximos a Manaus, os fitosteróides $\beta$-sitosterol, estigmasterol e os alcalóides oxoporfínicos (liriodenina e cassamedina).

Antônio et al. (1984) encontraram em folhas de plantas do Panamá, curzeronona (25,64\%), tipos e/ou produtos derivados da degradação da curzeronona $(42,31 \%)$, miristicina $(7,93 \%)$ e, principalmente, terpenóides no óleo essencial.

Estudos com folhas frescas de Rio Branco, no Acre, mostraram que o maior componente foi o óleo $\gamma$-cadineno $(21,8 \%)$, bergamotenal $(14,2 \%)$ e $\beta$ cariofileno (15,1\%), enquanto que nas folhas secas foi siparunona $(23,3 \%), \gamma$-cadineno $(12,7 \%)$ e isogermacrenona (12,2\%) (Rebouças, 1984).

Análises das partes aéreas de três populações coletadas em duas regiões do Pará, Mojú e Belém (amostras A e C, respectivamente) e uma em Rio Branco (amostra B), em época de floração, também apresentaram diferenças com relação à porcentagem do maior componente. $O$ maior constituinte dos óleos da amostra $A$ foi o epi- $\alpha$ bisabolol (25,1\%) e espatulenol (15,7\%). Na amostra $\mathrm{B}$, encontraram o espatulenol (22,0\%), selin-11-en-4$\alpha$-ol (19,4\%), $\beta$-eudesmol (10,0\%) e elemol $(10,0 \%)$. Para a amostra C, obtiveram o germaerona $(23,2 \%)$, germacrena B $(8,0 \%)$ e atractilona $(31,4 \%)$ (Zoghbi et al., 1998).

A influência das condições climáticas na composição do óleo da Siparuna foi observada por detecção de ampla variação dos componentes de óleos obtidos de plantas coletadas no estado de Rondônia durante diferentes meses do ano. Nerolidol foi o maior componente em junho, durante a floração, mas não foi encontrado em fevereiro (Machado et al., 1998).

Viana et al. (2002) fizeram trabalho inédito ao analisarem além de folhas e do caule, também casca do tronco, raiz e frutos da $S$. guianensis. No óleo da maior parte das plantas, foram identificados monoterpenos, sesquiterpenos, álcoois sesquiterpenos e duas cetonas alifáticas, 2-undecanona e 2tridecanona. $\mathrm{O} \alpha$-pineno, mirceno, $\gamma$-cadineno, epi- $\alpha$ cadinol estavam presentes em todas as amostras, mas o epi- $\alpha$-cadinol $(11,9$ - 39,9\%) foi sempre o maior componente, exceto para óleos das cascas e frutos, cujos maiores componentes foram respectivamente terpinoleno $(33,4 \%)$ e 2 -undecanona $(52,7 \%)$.

Fischer et al. (2005) estudaram os óleos essenciais das folhas e frutos desta espécie coletados no sudoeste do cerrado brasileiro e encontraram, como constituintes principais da folha, o ácido decanóico (46,6\%) e o 2-undecanona (31,7\%). O óleo da fruta consiste principalmente de 2-undecanona $(32,5 \%)$, $\beta$-pineno $(19,6 \%)$ e limoneno $(13,6 \%)$, contabilizando quase $65 \%$ dos constituentes. Todas as substâncias restantes contribuíram menos de 10\% para a composição do óleo da fruta. Nesse estudo, também foi observado que os óleos extraídos de amostras de espécies da Siparuna guianensis de duas regiões da Amazônia (Rebouças, 1984; Zoghbi et al., 1998) e uma do Panamá (Antônio et al., 1984) possuíam, como maior componente, os sesquiterpenos, enquanto que nas espécies do cerrado eram as metilcetonas e ácidos graxos. 
A ocorrência de variabilidade de produção de óleos essenciais da S. guianensis, visando o manejo sustentável da espécie, bem como o controle da matéria-prima, foi estudada através da produção de óleo essencial em função das partes vegetais (folhas e galhos) e da época de colheita (primavera, verão, outono e inverno) por Castellani et al. (2006). O material amostrado foi de mata da Silvicultura da Zona da Mata de Minas Gerais, e os resultados mostraram que a espécie não apresentou variação sazonal na produção de óleo essencial. Contudo, houve diferença significativa entre as partes vegetais analisadas, sendo que, nas folhas, ocorreu sempre maior produção de óleos essenciais. Em valores absolutos, no outono, ocorreu aumento de óleo essencial tanto nas folhas como nos galhos, estação em que a espécie começou a emitir botões florais, e, na primavera, fase de frutificação e brotação, os menores valores de óleo essencial.

\section{Propagação}

Van der Berg (1993) afirmou que a $S$. guianensis só se multiplicaria por sementes, e Davide et al. (1995) informaram que o peso médio de 100 sementes é $1,6 \mathrm{~g}$ e que a germinação observada foi abaixo de $30 \%$. Recomendou que, para extração das sementes, devem-se deixar os frutos imersos em água por 48 horas e, em seguida, macerar os frutos em peneira sob água corrente e secar as sementes à sombra em local ventilado.

Quanto à propagação vegetativa em outras espécies de Siparuna, as estacas de caules produziram facilmente novos caules (Feil, 1992), porém ainda não há informações na literarura sobre a propagação vegetativa da $S$. guianensis.

\section{CONCLUSÃO}

Como a Siparuna guianensis Aublet tem uma vasta indicação etnobotânica, e tem sido apontada como uma das espécies prioritárias de conservação para a região do cerrado brasileiro (Vieira \& Alves, 2003), os estudos de propagação devem ser incentivados, assim como, sistemas e práticas culturais para o cultivo, que são essenciais para que este recurso genético esteja disponível às gerações futuras.

\section{REFERÊNCIA}

ALBUQUERQUE, M.C.F. et al. Germinação de Sementes de Plantas Medicinais do Cerrado. In: COELHO, M.F.B. et al. (Eds.). Diversos olhares em etnobiologia, etnoecologia e plantas medicinais. Cuiabá: UNICEN Publicações, 2003. p.157-81.

ALVINO, F.O. et al. Potencial de uso das espécies arbóreas de uma floresta secundária, na Zona Bragantina, Pará, Brasil. Acta Amazônica, v.35, n.4, p.413-20, 2005.

ANTÔNIO, T.M. et al. Composition of essential oil from the leaves of Siparuna guianensis (Monimiaceae). Chemical Industries, v.14, p.514-5, 1984.

APPROBATO, A.U.; GODOY, S.A.P. Levantamento de diásporos em áreas de cerrado no Município de Luiz Antônio, SP. Hoehnea, v.33, n.3, p.385-401, 2006.

ARJONA, F.B. et al. Aspectos etnobotânicos e biogeografia de espécies medicinais e/ou rituais comercializadas no mercado de Madureira, RJ. Revista Caminhos da Geografia, v.8, n.23, p.41-50, 2007.

BOURDY, G. et al. Medicinal plants uses of the Tacana, an Amazonian Bolivian ethnic group. Journal of Ethnopharmacology, v.70, p.87-109, 2000.

BRAZ FILHO, R.et al. Oxoaporfine alkaloids from Fusea longifolia and Siparuna guianensis. Phytochemistry, v.15, p.1187-8, 1976.

CARMONA, P.F.; GUARIM NETO, G. As plantas medicinais, suas formas de uso e aplicabilidade fitoterápica: o saber tradicional. In: UNIVERSIDADE FEDERAL DO MATO GROSSO. Uso da Biodiversidade: Flora medicinal do cerrado do leste mato-grossense: uma abordagem etnobotânica. Relatório Técnico. Cuiabá: Instituto de Biociências. Departamento de Botânica e Ecologia, 2001. 21p.

CASTELLANI, D.C. et al. Produção do óleo essencial em catuaba (Trichilia catigua A. Juss) e negramina (Siparuna guianensis Aubl.) em função da época de colheita. Revista Brasileira de Plantas Medicinais, v.8, p.62-5, 2006.

CHRISTO, A.G. et al. Uso de recursos vegetais em comunidades rurais limítrofes à Reserva Biológica de Poço das Antas, Silva Jardim, Rio de Janeiro: Estudo de caso na Gleba Aldeia Velha. Rodriguésia, v.57, n.3, p.51942, 2006.

CIELO FILHO, R.; SANTIN, D.A. Estudo florístico e fitossociológico de um fragmento florestal urbanoBosque dos Alemães, Campinas, SP. Revista Brasileira de Botânica, v.25, n.3, p.291-301, 2002.

COSTA JÚNIOR, R.F. et al. Florística arbórea de um fragmento de Floresta Atlântica em Catende, Pernambuco - Nordeste do Brasil. Revista Brasileira de Ciências Agrárias, v.2, n.4, p.297-302, 2007.

DAVIDE, A.C. et al. Propagação de espécies florestais. Belo Horizonte: CEMIG/UFLA/FAEPE, 1995. 41p.

DUARTE, T.G. Um estudo etnoecológico sobre o uso de recursos vegetais em Nova Xavantina, Mato Grosso. 2001. 135p. Dissertação (Mestrado - Área de Concentração Ecologia e Conservação da Biodiversidade) Departamento de Botânica e Ecologia, Universidade Federal de Mato Grosso, Cuiabá.

DUKE, J.A. Duke's Handbook of Medicinal Plants of Latin America. New York: CRC Press Taylor \& Francis group, 2008. 832p.

FEIL, J.P.; RENNER, S.S. The pollination of Siparuna (Monimiaceae) by gall-midges (Cecidomyiidae): another likely ancient association. American Journal of Botany, v.78, p.186, 1991.

FEIL, J.P. Reproductive ecology of dioecious Siparuna (Monimiaceae) in Ecuador, a cane of gall midge polinattion. Botanical Journal of the Linnean Society, v.110, p.171-203, 1992.

FERREIRA, A.V. et al. Efeito da remoção de sementes

Rev. Bras. PI. Med., Botucatu, v.12, n.1, p.96-104, 2010. 
por formigas, aves e roedores no recrutamento de plântulas no cerrado. Resumo Expandido do XVIII Simpósio de Mirmecologia. Biológico, v.69, p.359-63, 2007.

FISCHER, D.C.H. et al. Essential oils from fruits and leaves of Siparuna guianensis (Aubl.) Tulasne from Southeastern Brazil. Journal of Essential Oil Research, v.17, n.1, p.101-4, 2005.

FONTELLE, M.G.L.C. Plantas medicinais utilizadas por raizeiros: uma abordagem etnobotânica no conteúdo da saúde e da doença. 1997. 141p. Dissertação (Mestrado - Área de Concentração Ecologia e Conservação da Biodiversidade) - Departamento de Botânica e Ecologia, Universidade Federal de Mato Grosso, Cuiabá

FURTADO, S.K. Alternativas fitoterápicas para o controle da verminose ovina no estado do Paraná: testes in vitro e in vivo. 2006.127p. Tese (Doutorado em Produção Vegetal) - Departamento de Fitotecnia e Fitossanitarismo, Setor de Ciências Agrárias, Universidade Federal do Paraná, Curitiba.

GAGNÉ, $R$. The gall midges of the neotropical region. New York: Cornell University Press, 1994. 352p.

GRENAND, P. et al. Pharmacopées traditionalles en Guyane: Créole: Palikur, Wayapi. Paris Editions de I'Orstom. 1987. 569p. In: LORENZI, H.; MATOS, F.J.A. Plantas medicinais no Brasil: nativas e exóticas. Nova Odessa: Instituto Plantarum, 2002. 544p.

GUARIM NETO, G.; MORAIS, R.G. Recursos medicinais de espécies do cerrado de Mato Grosso: um estudo bibliográfico. Acta Botânica Brasilica, v.17, n.4, p.56184, 2003.

HERRMANN, G. et al. Meio Biótico. Apa Carste de Lagoa Santa - MG. Belo Horizonte: IBAMA, CPRM e GERIDE, 1998. v.2, 92p.

JANGOUX, J. Novas espécies de Monimiaceae (Bracteanthus e Siparuna) do Brasil e das regiões limítrofes da Bolívia, da Colômbia e do Peru. Boletim do Museu Paraense Emílio Goeldi, v.7, n.1, p.115-52, 1991. KLINK, C.A.; MACHADO, R. Conservation of the Brazilian Cerrado. Conservation Biology, v.19, p.707-13, 2005.

LÔBO, D. et al. Espécies indicadas para recuperação de áreas degradadas na região da floresta atlântica ao norte do Rio São Francisco. Recife: CEPAN, 2007. 17p. MACHADO, S.M.F. et al. Seasonal variation of (E)nerolidol in Siparuna guianensis Aubl. and 13NMR Spectral Assignments of (E)- and (Z)- nerolidol. Journal of Essential Oil Research, v.10, p.708-10, 1998.

MARTINS FILHO, S.E.C. Avaliação dos danos e métodos de regulação da floresta submetida à exploração de impacto reduzido na Amazônia Oriental. 2006.120p. Dissertação (Mestrado em Ciências Florestais) - Universidade Federal Rural da Amazônia, Belém.

MILLIKEN, W.; ALBERT, B. The use of medicinal plants by the Yanomamy Indians of Brazil. Economic Botany, v.50, n.1, p.10-25, 1996.

NUNES, Y.R.F. et al. Variações da fisionomia, diversidade e composição de guildas da comunidade arbórea em um fragmento de floresta semidecidual em Lavras, MG. Acta Botanica Brasílica, v.17, n.2, p.213-29, 2003.

OLIVEIRA, P.E.A.M.; PAULA, F.R. Fenologia e biologia reprodutiva de plantas de matas de galeria. In: RIBEIRO, J.F. et al. Cerrado: caracterização e recuperação de Matas de Galeria. Planaltina: EMBRAPA Cerrados, 2001. p.303-28.

PASA, M.C. A utilização dos recursos vegetais no Vale do Aricá, Mato Grosso: um estudo etnoecológico. 1999. 150p. Dissertação (Mestrado - Área de Concentração Ecologia e Conservação da Biodiversidade) - Departamento de Botânica e Ecologia, Universidade Federal de Mato Grosso, Cuiabá.

PEÑA PAZ, A.A. Germinación de Siparuna aspera (Magnoliophyta: Siparunaceae) y polinización de Siparuna aspera, Siparuna laurifólia e Siparuna echinata. 2000. 162p. Tese (Doutorado - Área de concentração Botânica) - Faculdade de Ciências, Universidad Del Valle, Santiago de Cali.

PEREIRA, B.A.S.; SILVA, M.A. Lista de nomes populares de plantas nativas da região geoeconômica de Brasília, DF. Brasília: RECOR (reserva Ecológica do IBGE), 2002. Disponível em: <http://www.recor.org.br/publicacoes/ artigos.html>. Acesso em: 5 mai. 2008.

PINTO, L.V.A. et al. Estudo da vegetação como subsídios para propostas de recuperação das nascentes da bacia hidrográfica do Ribeirão Santa Cruz, Lavras, MG. Revista Árvore, v.29, n.5, p.775-93, 2005.

PRANCE, G.T. Ethnobotanical notes from Amazonia, Brazil. Economic Botany, v.26, n.3, p.221-37, 1972.

REBOUÇAS, L.M.C. Terpenos de Siparuna guianensis: aldeídos via epoxidação de duplas terminais. 1984. 116p. Dissertação (Mestrado em Química) - Faculdade de Química, Universidade Federal do Ceará, Fortaleza. RENNER, S.S. Laurales. Complement, Post-C3 (Lytic) Pathway-Encyclopedia of Life Sciences. St. Louis US: Macmillan Reference Ltd, 1997. 5p.

RENNER, S.S.; HAUSNER, G. Monograph of Siparunaceae: Flora Neotropica 95. New York: New York Botanical Garden, 2005. 256p.

RESSEL, K. et al. Ecologia morfofuncional de plântulas de espécies arbóreas da Estação Ecológica do Panga, Uberlândia, Minas Gerais. Revista Brasileira de Botânica, v.27, n.2, p.311-23, 2004.

ROCHA-COELHO, F.B.; SANTOS, M.G. Plantas medicinais utilizadas pela Comunidade Mumbuca Jalapão - TO: Um estudo etnofarmacológico. Pesquisa e Conservação do Cerrado. Disponível em: <http:// www.pequi.org.br/Coelho_\&_Santos.pdf.>. Acesso em: 5 mai. 2008.

RODRIGUES, L.A. et al. Espécies vegetais nativas usadas pela população local em Luminárias-MG. Boletim Agropecuário, n.52, p.1-34, 2002.

RODRIGUES, R.R. A vegetação de Piracicaba e municípios do entorno. Circular Técnica IPEF, n.189, p.1-17, 1999.

RODRIGUES, V.E.G.; CARVALHO, D.A. Levantamento etnobotânico de plantas medicinais no domínio do cerrado na região do Alto Rio Grande - Minas Gerais. Ciência e Agrotecnologia, v.25, n.1, p.102-23, 2001.

SANTOS, I.S.; PEIXOTO, A.L. Taxonomia do gênero Macropeplus Perkins (Monimiaceae, Monimioideae). Rodriguésia, v.52, n.81, p.65-105, 2001.

SCHIMÖLLER, E. Levantamento preliminar das plantas medicinais utilizadas pelos índios Bakairi, Aldeia Pakueran (Paranatinga, Mato Grosso). 1997. 55p. Monografia (Graduação - Instituto de Biologia) Universidade Federal de Mato Grosso, Cuiabá. 
SCHULZ-BURCK, D. Untersuchungen zur Morphologie und Biologie von Blueten der Gattung Siparuna Aubl. (Monimiaceae s.I.). 1997.147p. Dissertação (Mestrado) Univ. of Mainz, Germany. In: RENNER, S.S.; WON, H. Repeated evolution of dioecy from monoecy in Siparunaceae (Laurales). Systems Biology, v.50, n.5, p.700-12, 2001.

SIMAS, N.K. et al. Chemical ecological characteristics of herbivory of Siparuna guianensis seeds by buffy-headed marmosets (Callithrix flaviceps) in the Atlantic Forest of southeastern Brazil. Journal of Chemical Ecology, v.27, n.1, p.93-107, 2001.

SOMAVILLA, N.V. Utilização de plantas medicinais por uma comunidade garimpeira do Sudeste mato-grossense, Alto Coité - Poxoréo / Mato- Grosso. 1998. 93p. Dissertação (Mestrado - Área de Concentração Ecologia e Conservação da Biodiversidade) - Departamento de Botânica e Ecologia, Universidade Federal de Mato Grosso, Cuiabá.

SOUZA, C.D.; FELFILI, J.M. Uso de plantas medicinais na região de Alto Paraíso de Goiás, GO, Brasil. Acta Botanica Brasílica, v.20, n.1, p.135-42, 2006. SOUZA, L.F. Levantamento etnobotânico na localidade de São Gonçalo, Cuiabá, Mato Grosso, Brasil. 1992. 41p. Monografia (Graduação - Instituto de Biologia) Universidade Federal de Mato Grosso, Cuiabá.

SOUZA, P.A. et al. Avaliação do banco de sementes contido na serapilheira de um fragmento florestal visando recuperação de áreas degradadas. Revista Cerne, v.12, n.1, p.56-67, 2006.
SOUZA, P.B et al. Florística e estrutura da vegetação arbustivo-arbórea do sub-bosque de um povoamento de Eucalyptus grandis W. Hill ex Maiden em Viçosa, MG, Brasil. Revista Árvore, v.31, n.3, p.533-43, 2007.

TAKAHASI, A.; FINA, B.G. Síndromes de dispersão de sementes de uma área do Morro do Paxixi, Aquidauana, MS, Brasil. In: SIMPÓSIO SOBRE RECURSOS NATURAIS E SÓCIO-ECONÔMICOS DO PANTANAL, 4., 2004, Corumbá. Anais... Corumbá: UFMS, 2004. p.1-7.

VAN DEN BERG, M.E. Plantas medicinais na Amazônia: contribuição ao seu conhecimento sistemático. Belém: Museo Paraense Emílio Goeldi, 1993. 206p.

VIANA, F.A. et al. Essential oil of Siparuna guianensis Aublet from the Amazon Region of Brazil. Journal of Essential Oil Research, v.14, p.60-2, 2002.

VIANI, R.A.G.; RODRIGUES, R.R. Sobrevivência em viveiro de mudas de espécies nativas retiradas da regeneração natural de remanescente florestal. Pesquisa Agropecuária Brasileira, v.42, n.8, p.1067-75, 2007.

VIEIRA, F.R.; ALVES, R.B.N. Desafios para a conservação de recursos genéticos de plantas medicinais e aromáticas no Brasil. In: COELHO, M.F.B. et al. (Eds.). Diversos olhares em etnobiologia, etnoecologia e plantas medicinais. Cuiabá: UNICEN Publicações, 2003. p.157-81.

VIGNERON, M. et al. Antimalarial remedies in French Guiana: A knowledge attitudes and practices study. Journal of Ethnopharmacology, v.98, p.351-60, 2005. ZOGHBI, M.G.B. et al. Essential Oils of Siparuna guianensis Aubl. Journal of Essential Oil Research, v.10, p.543-6, 1998. 